\section{Lo esencial en la consulta} The essentials of medical consultation

Un editorial de Intensive Care Medicine de $2017^{1}$ predice que, para el 2050, los hospitales serán pequeños, con más camas de cuidados intensivos y robots que realicen muchas de las tareas médicas. Los autores auguran que todavía quedarán disciplinas en las que el contacto humano continuará siendo muy importante, como en... pediatría. Esto último nos habilita para seguir recordando pequeños detalles de la consulta.

Primero, hay que saber escuchar. "Los doctores saben hablar, pero no saben escuchar", es lo que sentencia Nanni Moretti en su film Caro Diario. Tener oídos abiertos al relato de síntomas, fechas, medicación, "terapias folklóricas" suele ser la llave que abre la puerta al diagnóstico. Cuando el niño puede hacerlo, debemos dar importancia a lo que cuenta. Y, desde el comienzo, estar atentos a la calidad del llanto, el tono de voz, la respiración quejosa, el timbre de la tos...

Después, hay que mirar. Antes de desenfundar el bajalenguas, debemos observar al niño. Ver si está atento o aletargado, irritable o quejoso. ¿Cómo es su tono muscular? ¿El color? ¿La respiración? Si no se hace esto antes de apoyar el frío estetoscopio, es probable que el lactante llore y se pierdan datos valiosos para diagnosticar una neumonía. Antes de que aparezca la radiografía con condensación para documentar la neumonía, hay datos que la anticipan y muchos de ellos están a la vista.

Después, tocar. La epidemia de gripe de 2009 dejó como "secuela positiva" la popularización del empleo del alcohol en gel. Nos permite higienizar nuestras manos, aunque el lavatorio del Centro de Atención Primaria de la Salud (CAPS) se encuentre a veinte metros del consultorio. Actualmente, no hay excusas para evitar tocar al paciente.

Hay que palpar el hígado en un niño que está recibiendo expansiones rápidas, con líquidos endovenosos, por un shock séptico; dejar que el polo de bazo vaya al encuentro de nuestros dedos en un bebé con una infección congénita; usar las manos para abrir las caderas en cada control y hasta que el lactante comience a caminar o para palpar una dureza bajo un eritema que duele...

Hay que dar vuelta los labios buscando llagas porque, si están, se podrá evitar medicar con antibióticos a un niño con faringitis y fiebre.
Y buscar los testículos en ascensor en un niño, arrodillándolo en posición de sastre. Cuando llegue a la Guardia un lactante con vómitos, llorando de dolor o por el contrario hipotónico, no debe omitirse meter el dedo en el recto (con el meñique alcanza). El tacto rectal es parte del examen y el pediatra no lo debe "tercerizar". Realizarlo permitirá palpar mejor un abdomen que genera dudas.

$Y$ aunque sea evidente que un problema emocional es el motivo de la consulta, no deje de tocar. Sus manos pueden tranquilizar a un niño angustiado, sin que ello lo convierta en un "manosanta".

También hay que oler. Usar el olfato permitirá distinguir el aliento cetónico del vomitador frecuente; el olor pútrido del niño que se puso gomaespuma en la nariz; el tufo de las heces del que tiene mala absorción; el olor a alcohol, tabaco o marihuana en un adolescente en riesgo y el olor a humo del que carece de calefactor para calentar su casilla.

Sobre gusto. Si bien lo intentamos, reconocemos que nunca pudimos diagnosticar una fibrosis quística de páncreas (FQP) por lo salado del sudor. Pero se puede emplear nuestra lengua para identificar los medicamentos amargos, para reemplazarlos por opciones más tomables $\mathrm{y}$, cuando estas no existan, aconsejar que previamente se apoye hielo sobre la lengua del niño para anestesiar las papilas gustativas.

Emplear las herramientas. A los cinco sentidos hay que ayudarlos. Los pediatras solemos alardear y quejarnos (al mismo tiempo): “¡Nosotros no usamos aparatos!". No se emplearán aparatos complejos, pero no es cierto que no se necesiten instrumentos.

Cuando los residentes van a los CAPS, siempre llevan sus estetoscopios $\mathrm{y}$, aun en los lugares más desprovistos, no carecen de un biauricular. Lo que suele faltar son otoscopios con pilas no agotadas, pediómetros adecuados, tensiómetros con mangos pequeños, hisopos para faringes, bajalenguas, para romperlos luego de usarlos, recetarios para evitar escribir detrás de cualquier papel de descarte. Algunos de los CAPS que nos tocó transitar mostraban muchas de las privaciones enunciadas. Las mismas que cuando se llamaban "dispensarios". Por eso, cuando el médico va a atender un consultorio público 
o privado, no debe olvidar llevar sus propias "herramientas". Un electricista que no cuente con sus pinzas y "buscapolos" generaría mucha desconfianza...

Al fin, hablar. No hay madres que "no entiendan"; hay médicos que no eligen las palabras adecuadas para ellas. Si la familia no comprende, se debe explicar empleando un lenguaje más accesible, recurrir a ejemplos, a dibujos. No por hablar con tonos muy fuertes se logra que una madre humilde mejore su atención; es más probable que le falte instrucción a que sea sorda.

Sin embargo, en el caso de niños con patologías graves, puede suceder que los padres "elijan" no comprender la mala noticia que se les está transmitiendo. Reconocer esta circunstancia es importante para sumar a la charla a otros familiares.

El pediatra debe hablar lo necesario; los padres buscan el mejor consejo, no que se les demuestre lo mucho que el médico sabe. Hay que enseñar los "signos de alarma" para que la familia sepa cuándo debe adelantar la consulta, pero también se debe informar sobre la evolución esperada de la enfermedad para evitar visitas innecesarias a la Guardia.

Antes de emitir un diagnóstico, hay que tomarse un tiempo. Frente a un niño con una patología en la piel, los padres preguntan enseguida: “¿Qué tiene?”. Pareciera que lo que está a la vista se diagnostica rápido. Ante cualquier exantema dudoso, ¡no caiga en la "trampa de la inmediatez"! No hay que apresurase. Un buen truco es colocar un termómetro en la axila. Ante esta circunstancia, los padres suelen esperar, y usted tendrá cuatro valiosos minutos para pensar.

Muchas veces, es imposible realizar el diagnóstico cuando aparecen los primeros síntomas. Excepto en el paciente crítico, el médico debe permitirse un tiempo para ver la evolución y los padres, por lo general, entenderán si les explica y programa una nueva consulta.

Y no hay que olvidarse de los prejuicios. Los de los pacientes y los propios. Como parte de la consulta, Carlos Gianantonio recomendaba averiguar la hipótesis de la familia sobre lo que le pasaba al niño. Por acertada que sea la presunción diagnóstica del médico, este debe demostrar a los padres que su hipótesis es mejor que la que ellos traen. De esa manera, serán mejor aceptadas todas las indicaciones.
Los pediatras somos vulnerables a nuestros propios prejuicios. Contaba Lawrence Nazarian, antiguo editor de Pediatrics in Review, que los jóvenes recién salidos de la residencia, ante todo cuadro febril en un lactante, pensarían en la posibilidad de sepsis y, en un niño con rasgos algo peculiares, sospecharían un síndrome raro, aunque las mismas características estuvieran presentes en el padre. Esta actitud resulta comprensible en quienes pasan cuatro años viendo a niños que, en efecto, tienen enfermedades serias. A su vez, un pediatra que, durante décadas, ha examinado a pacientes sanos y con enfermedades autolimitadas adquiere el prejuicio de que "probablemente, nada es grave". La mayoría de las veces será así, pero, en ocasiones, cuando menos se espera, el niño que siempre ha crecido sano debuta con diabetes, cáncer, depresión y encuentra al pediatra experimentado con la guardia baja.

Mezclar pediatras viejos con los jóvenes es, sin dudas, una asociación gratificante y beneficiosa para todos y, especialmente, para el niño.

Resumiendo, lo esencial en la consulta pediátrica es un pediatra capacitado, capaz de utilizar todos sus sentidos. A su vez, resulta primordial promover estrategias para lograr que, en todo el país, los niños sean atendidos por pediatras.

\section{Agradecimiento}

Para quienes comenzaron el aprendizaje de la pediatría en el Hospital de Niños de Santa Fe. En memoria de los médicos pediatras Federico Milia, Ángel Spedaletti y Abel Argento.

Médico Pediatra Juan Carlos Beltramino

Ex director de Docencia e Investigación del Hospital de Niños “Dr. O. Alassia” de Santa Fe.

http:/ / dx.doi.org/10.5546/ aap.2018.236

Texto completo en inglés:

http:/ / dx.doi.org/10.5546/aap.2018.eng.236

Cómo citar: Beltramino JC. Lo esencial en la consulta. Arch Argent Pediatr 2018;116(4):236-237.

\section{REFERENCIA}

1. Vincent JL, Slutsky AS, Gattinoni L. Intensive care medicine in 2050: the future of ICU treatments. Intensive Care Med 2017; 43(9):1401-2. 